\title{
REFORMAS, DOCÊNCIA E VIOLÊNCIA CURRICULAR: UMA ANÁLISE A PARTIR DO "NOVO ENSINO MÉDIO"
}

\author{
REFORMAS, DOCENCIA Y VIOLENCIA CURRICULAR: UN ANALISIS A PARTIR \\ DE LA "NUEVA EDUCACIÓN SECUNDARIA"
}

\author{
REFORMS, TEACHING AND CURRICULAR VIOLENCE: AN ANALYSIS FROM THE \\ "NEW HIGH SCHOOL"
}

\author{
Éder da Silva SILVEIRA ${ }^{1}$ \\ Monica Ribeiro da SILVA ${ }^{2}$
}

Falconiere Leone Bezerra de OLIVEIRA ${ }^{3}$

RESUMO: Neste artigo busca-se compreender o que comunicam as narrativas de professores/as que atuam em duas escolas-piloto do programa do governo federal criado com vistas à implementação da reforma do ensino médio (Lei 13.415/17) e em uma escola privada que vem implementando a reforma a título experimental. A análise se centra em perspectiva conceitual que se propõe a identificar as violências que se manifestam nesse novo currículo para o exercício da docência. Trata-se de pesquisa qualitativa, baseada na realização e análise de três entrevistas com dois professores e uma supervisora, contemplando três escolas situadas no estado do Rio Grande do Sul. Argumenta-se que o currículo do chamado Novo Ensino Médio tem produzido diferentes formas e manifestações de Violência Curricular e, por esse motivo, impõe obstáculos ao exercício da docência e à formação humana em perspectiva crítica.

PALAVRAS-CHAVE: Reforma do ensino médio. Docência. Violência curricular.

RESUMEN: Este artículo busca entender cuáles son las narrativas de los maestros que trabajan en dos escuelas piloto del programa del gobierno federal creado con miras a implementar la reforma de la enseñanza secundaria (Ley 13,415/17) y en una escuela privada que ha estado implementando la reforma de manera experimental. El análisis se centra en una perspectiva conceptual que tiene como objetivo identificar la violencia que se manifiesta en este nuevo currículo para el ejercicio de la docencia. Se trata de una investigación cualitativa, basada en la realización y análisis de tres entrevistas con dos docentes y un supervisor de tres escuelas ubicadas en el estado de Rio Grande do Sul. Se argumenta que el currículo de la llamada Nueva Educación Secundaria (Novo Ensino

\footnotetext{
${ }^{1}$ Universidade de Santa Cruz do Sul (UNISC), Santa Cruz do Sul - RS - Brasil. Professor do Programa de PósGraduação em Educação. Em estágio de Pós-Doutoramento no Programa de Pós-Graduação em Educação (UFPR). ORCID: https://orcid.org/0000-0002-1242-2126.E-mail: eders@unisc.br

${ }^{2}$ Universidade Federal do Paraná (UFPR), Curitiba - PR - Brasil. Professora do Programa de Pós-Graduação em Educação. Pós-Doutorado em Educação (UNICAMP). Pesquisadora do CNPq Bolsista Produtividade PQ 1D. ORCID: https://orcid.org/0000-0002-1729-8742 E-mail: monicars@ufpr.br

${ }^{3}$ Universidade de Santa Cruz do Sul (UNISC), Santa Cruz do Sul - RS - Brasil. Doutorando no Programa de Pós-Graduação em Educação. ORCID: https://orcid.org/0000-0002-5538-4369. E-mail: falconiereleone@mx2.unisc.br
} 
Médio) ha producido diferentes formas y manifestaciones de violencia curricular y, por esta razón, impone obstáculos al ejercicio de la docencia y a la formación humana en una perspectiva critica.

PALABRAS CLAVE: Reforma de la educación secundaria. Docencia. Violencia curricular.

ABSTRACT: This article seeks to understand what is communicated in the narratives of teachers who work in two pilot schools of the federal government program created to implement the high school reform (Law 13.415/17) and in a private school that has been implementing the reform on an experimental basis. The analysis focuses on a conceptual perspective that aims to identify the violence that manifests itself in this new curriculum for the exercise of teaching. This is a qualitative research, based on the realization and analysis of three interviews with two teachers and a supervisor from three schools located in the state of Rio Grande do Sul. It is argued that the curriculum of the so-called New High School has produced different forms and manifestations of Curricular Violence and, for this reason, imposes obstacles to the exercise of teaching and human formation in a critical perspective.

KEYWORDS: High school reform. Teaching. Curricular violence.

\section{Introdução}

O Ensino Médio no Brasil tem sido palco de várias tentativas de reformulação, sobretudo a partir da última Lei de Diretrizes e Bases da Educação (Lei 9.394/96). Em pouco mais de 20 anos, para dar destaque a algumas dessas iniciativas, foram três diretrizes curriculares com referências conceituais e propositivas distintas exaradas pelo Conselho Nacional de Educação, um Projeto de Lei (PL 6.840/13), dois Decretos com regulamentações diferentes acerca da relação com a educação profissional, e, mais recentemente, uma medida provisória (MP 746/16, aprovada como Lei 13.415/17), que desencadeia um amplo processo de reforma curricular e das regras de financiamento desta etapa final da educação básica (BRASIL, 2017).

De um ponto de vista histórico, o Ensino Médio foi marcado por mudanças frequentes em suas regulações normativas que se mostraram incapazes de solucionar dificuldades e necessidades das juventudes, ou mesmo de resolver as contradições que acompanharam até hoje a etapa final da Educação Básica, historicamente marcada por movimentos pendulares quanto à formação propedêutica e profissional e quanto às suas finalidades. Desafios relativos à docência, incluindo os referentes "[...] à formação de professores, à superação da dualidade estrutural e à diminuição da precarização do trabalho docente, fazem do Ensino Médio uma pauta constantemente atualizada no campo do debate educacional brasileiro" (SILVEIRA; RAMOS; VIANNA, 2018, p. 102). 
No cenário mais recente, as várias propostas de reformulação são compreendidas, também, devido à expressiva ampliação do acesso ao sistema escolar por parte de uma juventude até então negligenciada quanto ao direito à educação. O país passa de uma situação em que menos de $25 \%$ da faixa etária considerada apropriada cursava o Ensino Médio para um percentual acima de 70\%. E isso ocorreu em pouco mais de 20 anos, incentivado, principalmente, pela Emenda Constitucional 59/2009, que tornou obrigatória a matrícula de todas as pessoas entre quatro e 17 anos, incluindo, portanto, a idade destinada ao Ensino Médio. Esses dados, no entanto, quando confrontados com a Meta 3 do Plano Nacional de Educação, de inclusão de $85 \%$ da faixa etária de 15 a 17 anos nessa etapa até 2024, sinalizam para o descumprimento da meta, tendência acentuada quando se verifica que, mesmo em face de toda a expansão ocorrida, no ano de 2020 mais de um milhão de jovens em idade escolar obrigatória encontravam-se sem qualquer vínculo escolar (SILVA, 2020). É nesse quadro que se vê aprovada a Lei 13.415/17 (BRASIL, 2017).

Com a reforma, passa a constar no artigo 36 da LDB, reformulado pela Lei n. 13.415 de 2017, que o currículo do Ensino Médio brasileiro passa a ser dividido em duas partes: a primeira, vinculada ao documento de Base Nacional Comum Curricular (BNCC) e com carga horária até o limite de 1.800 horas; e a segunda, composta por "itinerários formativos", dos quais cada estudante cursa apenas um. Com isso, a carga horária total passa das atuais 2.400 horas para 3.000 horas.

O novo texto da LDB informa que são os sistemas e instituições de ensino que oferecerão um número mínimo de itinerários para a realização da "escolha". Isto é, as alterações asseveram que os itinerários, também nomeados de "percursos", "deverão ser organizados por meio da oferta de diferentes arranjos curriculares, conforme a relevância para o contexto local e a possibilidade dos sistemas de ensino" (BRASIL, 2017, s/p). Como efeito prático, cada estado e rede de ensino definem qual(is) itinerário(s) formativo(s) será(ão) oferecido(s), possibilitando, por exemplo, que um(a) aluno(a) que estude em uma escola em que não seja oferecido determinado itinerário, e não tenha meios para se deslocar para uma comunidade escolar que o ofereça, não terá, efetivamente, oportunidade de escolha para cursar o percurso de sua preferência.

São muitas as novas/velhas questões relativas ao Ensino Médio suscitadas pelo atual contexto em face das novas regulamentações. Uma delas diz respeito à recuperação do discurso presente nas diretrizes e parâmetros curriculares da década de 1990, referente à proposição do currículo organizado com base na prescrição de competências, "que reintroduz os limites já identificados em pesquisas anteriores, dentre eles, o de que tal abordagem 
mostra-se limitada por seu caráter pragmático e a-histórico". (SILVA, 2018, p. 1). Padronização, formação administrada, enfraquecimento do Ensino Médio como educação básica (SILVA, 2018), e a perda de autonomia das escolas somam-se a novos problemas que intensificam a precarização e descaracterizam o trabalho docente.

Em 2019, a partir da indução feita pela Portaria $n^{0} 649$ (BRASIL, 2018a), do Ministério da Educação que cria o Programa de Apoio ao Novo Ensino Médio, são designadas unidades escolares para assumirem o papel de escolas-piloto do Novo Ensino Médio. Essas escolas passam a se orientar a partir dos documentos exarados com vistas à implementação da reforma curricular, que incluem, entre outros dispositivos, a Lei 13.415/2017 (BRASIL, 2017) e suas alterações na Lei de Diretrizes e Bases da Educação Nacional em vigor (BRASIL, 1996), as Diretrizes Curriculares Nacionais para o Ensino Médio - DCNEM (BRASIL, 2018b), a Portaria 1.432/2018, que estabelece Referenciais Curriculares para a Elaboração de Itinerários Formativos (BRASIL, 2018c) e a Base Nacional Comum Curricular (BRASIL, 2018d). O objetivo do Programa é o de dar suporte financeiro à implementação da BNCC e dos itinerários formativos, bem como à ampliação da carga horária total para um mínimo de 3.000 horas em três anos. Os repasses dos recursos financeiros são feitos via FNDE diretamente às escolas, por meio do Programa Dinheiro Direto na Escola (PDDE).

Em 2019, 21 das 27 unidades da federação começaram, por meio das respectivas secretarias estaduais de educação e coordenadorias e/ou unidades regionais de ensino, a indicar as suas escolas-piloto para aquilo que passou a ser chamado de "Novo Ensino Médio" ou "NEM". No Rio Grande do Sul foram escolhidas cerca de 300 escolas-piloto, que foram divididas em grupos de 10 instituições por Coordenadoria Regional de Educação (CRE). Nesse mesmo ano, iniciamos uma observação participante em reuniões e momentos de formação com supervisores e diretores das escolas-piloto vinculadas a uma CRE do referido estado. Em 2020, em virtude da pandemia da Covid-19, passamos a realizar entrevistas com professoras e supervisoras do mesmo grupo de escolas-piloto dessa CRE, via google meet. Essas entrevistas estão compondo um acervo de fontes orais em nosso grupo de pesquisa para projetos que estamos desenvolvendo acerca da implementação da reforma.

A fim de compreender o que comunicam as narrativas de professores(as) de escolaspiloto a respeito da docência e do currículo do Novo Ensino Médio no campo da prática, e de identificar quais violências se manifestam nesse novo currículo para o exercício da docência, analisamos três entrevistas realizadas com os seguintes sujeitos: a) um professor de História de uma escola-piloto do NEM da rede pública estadual de ensino do RS; b) um professor de História de uma escola que iniciou em caráter experimental a oferta do NEM de uma rede 
privada de educação; c) uma supervisora de outra escola-piloto do NEM da rede pública estadual de educação do RS. Os professores foram identificados, respectivamente, como “Alessandro" e "Leandro" - pseudônimos utilizados a fim de respeitar a preferência destes sujeitos pelo anonimato, conforme o Termo de Consentimento Livre e Esclarecido. A supervisora Caroline Salgueiro foi devidamente identificada, respeitando sua preferência pelo não anonimato. As entrevistas foram gravadas via google meet, no ano de 2020. Cada entrevista teve duração média entre 100 e 110 minutos. As questões abordadas incluíam perguntas sobre o novo currículo, a trajetória do Novo Ensino Médio em cada uma das escolas nos dois primeiros anos, mudanças na docência e relações com as proposições presentes na reforma: BNCC, Itinerários Formativos, projeto de vida. Buscamos dimensionar, também, expectativas e frustrações com relação à reforma curricular. As respostas foram transcritas e revisadas conforme preceitos da História Oral (PORTELLI, 2001; 1997), sendo analisadas a partir de categorização inspirada na Análise de Conteúdo (BARDIN, 2011).

Teoricamente, localizamos a análise no âmbito das Teorias Críticas do Currículo e fazemos uso de uma categoria analítica denominada Violência Curricular, desenvolvida por Valter Giovedi (2016). A rigor, argumentamos que o currículo do Novo Ensino Médio tem produzido diferentes formas e manifestações de Violência Curricular e, por esse motivo, impõe obstáculos ao exercício da docência, na perspectiva crítica, e à formação, na perspectiva da emancipação humana.

O presente texto está dividido em três seções. Na primeira, apresentamos, de forma concisa, o que entendemos como Docência e Violência Curricular. Na segunda e na terceira seção analisamos o conjunto de narrativas dos entrevistados, a partir da perspectiva teórica desenvolvida, demonstrando as razões pelas quais o Novo Ensino Médio pode ser visto como violência contra a autonomia das escolas e dos(as) docentes, contra o direito ao conhecimento e contra o trabalho docente. Essas violências, consideradas expressões da Violência Curricular, comunicam os efeitos da reforma no campo da prática da docência e do novo currículo.

\section{Docência e Violência Curricular: notas em perspectiva crítica}

Entendemos currículo a partir de uma perspectiva crítica. Currículo é poder (APPLE, 2006; 2011), é campo de resistência (GIROUX, 1986), é território em disputa (ARROYO, 2013), e nele se expressam problemas sociais, éticos e políticos. Como observou, ainda, Ana Maria Saul, "currículo é, na acepção freireana, a política, a teoria e a prática do que-fazer na 
educação, no espaço escolar, e nas ações que acontecem fora desse espaço, numa perspectiva crítico-transformadora" (SAUL, 2015, p. 222). Nessa perspectiva, como destaca Giovedi, ele "se manifesta, se realiza e se concretiza em todas as políticas, nas intenções declaradas e nas práticas" (2016, p. 121) e não se limita aos espaços formais, pois existe "nas diferentes formas das manifestações educativas" (2016, p. 82).

O currículo que nega a existência do ser humano e de sua dignidade, que o torna subalterno, ou que reproduz relações de dominação e subordinação é produtor de violências e sentidos contrários ao exercício da docência em perspectiva crítica. Por outro lado, mesmo tendendo à reprodução de relações de dominação e subordinação, currículo é, ao mesmo tempo, campo de experiências de resistência, de desenvolvimento de práticas curriculares que reafirmam a existência de homens e mulheres como sujeitos de emancipação. Afinal, "compreender o currículo como portador, ao mesmo tempo, de uma razão que tem privilegiado a adaptação, mas que, contraditoriamente, anuncia a possibilidade de emancipação, permite tomar a escola como depositária das contradições que permeiam a sociedade" (SILVA, 2008, p. 32).

Por ser um espaço de correlações de diferentes forças que atuam na elaboração de concepção de mundo, de sociedade e de ser humano, o currículo também se constitui nas disputas, nos conflitos gerados pela hegemonia e pelos consensos que vão sendo construídos em torno de termos, significados e práticas. Nesse sentido, como destacaram Lima e Pernambuco $(2018$, p. 5), sobre o currículo também recaem as palavras docência, educação, escola, conhecimento, as quais, "além de constituírem o vocabulário pedagógico [...], condicionam a ação formativa escolar que, por sua vez, produz efeitos de poder sobre pessoas, construindo identidades e subjetividades sociais específicas".

A docência diz respeito ao trabalho desenvolvido por professores e professoras e aos processos formativos que lhes permitem construir e desenvolver os saberes considerados necessários para mediar processos educativos. "Etimologicamente, o termo docência significa ação de ensinar e está vinculado ao radical do verbo latino docere, cujo sentido se expressa por ensinar, instruir, mostrar, indicar, dar a entender" (VEIGA, 2005, p. 39).

Como destacou Imbernón (2001, p. 39), no exercício da docência como profissão, os conhecimentos dos professores e das professoras se colocam "a serviço da mudança e da dignificação da pessoa". Logo, "ser um profissional da educação significa participar da emancipação das pessoas. O objetivo da educação é ajudar a tornar as pessoas mais livres, menos dependentes do poder econômico, político e social. E a profissão de ensinar tem essa obrigação intrínseca" (IMBERNÓN, 2001, p. 39). Mas, seria esta concepção de docência 
possível no Novo Ensino Médio? O que dizem as experiências recentes com o novo currículo sobre as condições de possibilidade do exercício de uma docência nesta perspectiva crítica?

É importante explicitar o que estamos entendo como perspectiva "crítica". Entendemos, conforme Nobre (2004, p. 10), que um dos sentidos fundamentais desta palavra, à luz das Teorias Críticas, é o seguinte: a crítica implica em "um ponto de vista capaz de apontar e analisar os obstáculos a serem superados para que as potencialidades melhores presentes no existente possam se realizar" (NOBRE, 2004, p. 10). O ponto de vista crítico é também, em sentido complementar, "aquele que vê o que existe da perspectiva do novo que ainda não nasceu, mas que se encontra em germe no próprio existente.”

A tarefa primeira da Teoria Crítica é, portanto, a de apresentar 'as coisas
como são' sob a forma de tendências presentes no desenvolvimento
histórico. E o delineamento de tais tendências só se torna possível a partir da
própria perspectiva de emancipação, da realização de uma sociedade livre e
justa, de modo que 'tendência' significa, então, apresentar, a cada vez, em
cada momento histórico, os arranjos concretos tanto dos potenciais
emancipatórios quanto dos obstáculos à emancipação (NOBRE, 2004, p. 11).

A expressão "Teoria Crítica" pode assumir sentidos diferentes. Pode ser entendida como um campo teórico composto por autores e abordagens distintas, como tradição de pensamento ou abordagem ligada ao materialismo histórico e sua renovação/atualização, ou como referência à Escola de Frankfurt - identidade e/ou tradição de pensamento que se formou a partir de um grupo de intelectuais que se uniram em torno do Instituto de Pesquisa Social, fundado em 1923, com a finalidade de estudar, interdisciplinarmente, a obra de Karl Marx. Essa expressão apareceu pela primeira vez em um artigo de Max Horkheimer (18951973), intitulado "Teoria Tradicional e Teoria Crítica”, publicado em 1937 (NOBRE, 2004; PUCCI, 1995).

De modo geral, os intelectuais da Teoria Crítica ou Teoria Crítica da Sociedade - T. W. Adorno, M. Horkheimer, H. Marcuse e W. Benjamin -, a partir do contexto da ascensão do nazifascismo, denunciam a transformação do princípio da razão emancipatória em razão instrumental no capitalismo. Nesse sentido, a Teoria Crítica apresenta-se como denúncia e anúncio, defendendo que a razão humana se oponha à razão instrumental e favoreça a realização da autonomia, a conscientização, o fim do positivismo, a libertação das formas de dominação e uma nova relação entre teoria e prática, entre pensamento e ação.

Em termos educacionais, a Teoria Crítica anuncia, conforme Adorno (1995), que a formação humana tem se limitado a educar quase que exclusivamente para a adaptação à sociedade. Os processos formativos assentados na razão produzida pelo esclarecimento, pela 
razão instrumental dele derivada, limitam a capacidade de condução à autorreflexão crítica e à identificação dos mecanismos de dominação, impedindo que a educação se realize em sua completude, em sua dupla finalidade, de adaptação e emancipação.

Inspirados nos enunciados da Teoria Crítica, buscamos realizar uma análise crítica das narrativas que serão apresentadas na próxima seção. Essa análise tem como uma de suas funções principais a de "iluminar os modos pelos quais a política e a prática educacionais estão conectadas às relações de exploração e dominação - e às lutas contra tais relações - na sociedade como um todo" (APPLE; AU; GANDIN, 2011, p. 15). Segundo esses autores, trata-se de uma análise que "deve apontar para as contradições e para os espaços de ação possíveis $[. .$.$] que enfatize os espaços nos quais ações contra-hegemônicas possam se realizar$ ou de fato se realizem [...]" (APPLE; AU; GANDIN, 2011, p. 15). Isto porque, na análise crítica, uma importante tarefa é "a produção de um determinado diagnóstico do tempo presente $[. .$.$] em que se mostram tanto as oportunidades e potencialidades para a emancipação$ quanto os obstáculos reais a ela" (NOBRE, 2004, p. 11). Considerando os limites deste texto e o desejo de valorizarmos as narrativas dos entrevistados, nossa análise terá como enfoque a produção desse diagnóstico, ficando o eixo das ações contra-hegemônicas e dos espaços de ação possíveis como uma dimensão a ser perseguida em outro momento, pois mereceria aprofundamento da pesquisa a partir de novos objetivos e dados empíricos.

Entendemos que esse diagnóstico, considerando os pressupostos teóricos brevemente enunciados, pode ser constituído com as narrativas dos docentes analisadas a partir da categoria Violência Curricular, assim conceituada por Giovedi (2016, p. 120, grifos nossos):

[...] a violência curricular consiste nas várias maneiras pelas quais os elementos e processos que constituem o currículo escolar - suas práticas e intenções políticas, seus valores difundidos (declarados ou não); sua concepção de aprendizagem praticada (declarada ou não), seus objetivos de formação praticados (declarados ou não), seus conteúdos selecionados, seu modo de organização do tempo, seu modo de organizar o espaço, suas metodologias, seus processos de avaliação, a relação professor-alunos etc. negam as possibilidades dos sujeitos da educação escolar reproduzirem e desenvolverem as suas vidas de maneira humana, digna e em comunidade.

Violência, na concepção de Giovedi (2016, p. 40), assume a dimensão de "um fenômeno explícito ou sutil de negação da vida humana na sua possibilidade de reprodução e desenvolvimento". Dessa forma, a violência curricular se realiza no cotidiano das instituições de ensino, no e por meio do currículo. Nas palavras do autor, o conceito "enfatiza o caráter violento das significações que são impostas aos receptores da ação pedagógica". Trata-se de 
um conceito que, como defende Giovedi, "incorpora os processos de violência que se sobrepõem aos profissionais da educação que estão submetidos também a outros processos violentos, sem prejuízo, obviamente, dos processos de violência simbólica", processos estes desenvolvidos por Bourdieu (GIOVEDI, 2016, p. 70).

Com a articulação das perspectivas de Dussel (1993), Freire (2005) e Candau (2000), o conceito de violência encontrado em Chauí (2006; 2007), Charlot (2002) e em Bourdieu e Passeron (2008) é ampliado por Giovedi, e o leque de possibilidades de compreensão desse conceito ganha contornos mais abrangentes para estudos sobre o currículo escolar. $\mathrm{Na}$ concepção desse autor, a violência é, "em sentido bastante amplo, como sendo toda negação (por parte das normas, ações, microestruturas, instituições e sistemas de eticidade) dos princípios ético-material, moral formal e de factibilidade ética” (GIOVEDI, 2016, p. 119).

Em seu estudo, Giovedi identificou 12 formas específicas de manifestações da violência curricular: 1) "Violência contra a identidade cultural": quando o currículo produz padronização e homogeneização; 2) "Violência contra a identidade individual": quando um único ritmo e padrão de aprendizagem serve de parâmetro na prática educativa; 3 ) "Violência contra a pulsão criadora": quando, por imposição, trabalhadores da educação e alunos ocupam boa parte de seu tempo com atividades de caráter repetitivo e burocrático; 4) "Violência contra a vida em comunidade": quando o currículo estimula a competição, a comparação, o ranqueamento; 5) "Violência contra a pulsão de alteridade": quando, por exemplo, o currículo privilegia agrupamentos exclusivamente por idade e divisão dos alunos em séries; 6) "Violência contra a pulsão de autoconservação": quando o currículo produz formas de controle dos corpos, promovendo condições de trabalho desumanas; 7) "Violência contra a integridade moral e psíquica": quando o cotidiano do currículo escolar é marcado por formas de tratamento inadequadas ou injustas, com desprezo, intimidação ou indiferença; 8) "Violência contra o desenvolvimento da potencialidade intelectual": quando há formas de omissão diante da percepção de que o aluno não aprendeu; 9) "Violência contra a participação simétrica no processo decisório": quando há procedimentos de exclusão de sujeitos do currículo dos processos que exigem tomadas de decisão; 10) "Violência discursivoideológica": quando sujeitos do currículo produzem discursos de rotulação e culpabilização Giovedi exemplifica com situações ocorridas em sala de professores e conselhos de classe no cotidiano escolar; 11) "Violência contra as condições de funcionamento": quando há ação ou omissão destruidora, como geralmente se percebe quando há falta de recursos e investimentos na infraestrutura das escolas; 12) "Violência contra o patrimônio": quando existem ações de 
depredação ou desrespeito com o patrimônio público representado ou salvaguardado pela escola (GIOVEDI, 2016).

\section{O Novo Ensino Médio como violência contra a autonomia da escola e dos(das) docentes}

Nas relações e práticas concretas estabelecidas na implementação da reforma do Ensino Médio nas escolas-piloto ocorrem diferentes mecanismos e formas de manifestação de violência curricular, conforme narram os sujeitos entrevistados. Os professores e a professora comunicam diferentes obstáculos para o exercício da docência no sentindo da emancipação e da dignidade humana. Argumentamos, nesta seção, que esses obstáculos constituem formas de violência curricular vivida nas escolas-piloto do Novo Ensino Médio.

Uma das formas de manifestação da violência promovida no novo currículo diz respeito à dimensão da autonomia da escola e dos docentes. Essa falta de autonomia ocorre tanto na rede pública quanto na rede particular de ensino, conforme descrevem os sujeitos ao se referirem à $\mathrm{BNCC}$ e aos itinerários formativos.

Leandro, professor de história de uma escola-piloto do NEM de uma rede privada de ensino, destacou: "É a gerência de educação [da rede] que vai decidir como vai ser feito esse trabalho de apropriação da BNCC". E o entrevistado continua:

[...] vários professores ficaram muito chateados porque veio pronto para o ensino fundamental todas as habilidades que devem ser trabalhadas. As professoras do fundamental, que são as profes do currículo, tiveram que fazer tudo isso para todos os componentes. Deu uma trabalheira imensa para essas mulheres e, agora, veio pronto da gerência de educação, alterando tudo aquilo que elas fizeram [...]. Para nós do médio não, só que a gente está utilizando do sistema [da rede] de educação (LEANDRO, 2020).

Na rede pública estadual de ensino do RS, Caroline, supervisora de uma escola-piloto, disse que "a escola começa a ficar desacreditada nesse momento". Ela explica que o processo da "implementação" do Novo Ensino Médio na rede pública estadual começou em 2019, quando as escolas receberam como tarefa fazer um exercício de flexibilização curricular, com 100 minutos semanais. Nesses minutos, os alunos deveriam experimentar oficinas e outras atividades diferentes dentro da escola, com temas que partissem dos seus centros de interesse e da comunidade escolar, a fim de mapear os percursos formativos ${ }^{4}$ ou a temática desses percursos junto à comunidade, pois havia o discurso de que os futuros itinerários da parte diversificada do currículo deveriam emergir da própria escola. Segundo Caroline, a suposta

\footnotetext{
${ }^{4}$ As matrizes curriculares e outros documentos da rede pública estadual do estado do Rio Grande do Sul usam a expressão "percursos formativos" referindo-se aos "itinerários formativos" descritos no marco regulatório nacional do Novo Ensino Médio. Neste artigo, as expressões serão consideradas sinônimos.
} 
liberdade dada às escolas-piloto, em 2019, gerou muito entusiasmo e planejamento na escola, que passou a realizar oficinas diferenciadas. "Teve uma das oficinas, [...] que a escola virou Machado de Assis! A gente teve aqui uma encenação do conto "A cartomante" [...] foi maravilhoso! [...] Depois a gente fez sobre jornalismo [...], foram muito dinâmicas", comentou a supervisora.

No entanto, antes mesmo de a escola concluir sua experiência de flexibilização curricular, houve uma determinação por parte do governo do estado do RS de que as oficinas deveriam ser realizadas dentro de 10 temas específicos, vinculados aos itinerários que seriam definidos e assumidos na rede. Ou seja, aquilo que a escola já vinha construindo foi interrompido em determinado momento, em 2019. E, disse a supervisora,

\begin{abstract}
[...] nós passamos no ano passado, exaustivamente, tendo que criar material, criar oficina, fazer atividades de 100 minutos semanais ou quinzenais, de atividades com alunos do oitavo e do nono ano. Inclusive, oferecer também aos do município para que eles tivessem uma noção de como seria esse Novo Ensino Médio. Muito bem, fizemos tudo isso. Só que o que que aconteceu? Quando nós selecionamos alguns professores para irem até Porto Alegre para trabalhar em cima de como montaria esse Percurso Formativo, a escola perdeu totalmente autonomia. Por que que perde autonomia? Porque veio ali tais e tais percursos formativos e a escola vai ter que se encaixar dentro desses percursos formativos. [...] A gente já tinha pensado em organizar a escola de maneira semestral, enfim, realmente nós pensávamos que teríamos autonomia para fazer essa escola mais atrativa e que o aluno tivesse oportunidade de experimentar, só que não é isso que acontece (SALGUEIRO, 2020).
\end{abstract}

Esses exemplos podem ser lidos como formas de manifestação de violência curricular. Considerando a classificação identificada por Giovedi (2016), podemos perceber que os docentes vivem a "violência contra a participação simétrica no processo decisório", pois narram procedimentos de exclusão de sujeitos da escola dos processos que exigem tomadas de decisão importantes em relação ao currículo. As narrativas de Leonardo e Caroline também representam duas outras formas de manifestação da violência curricular, denominadas pelo mesmo autor de "violência contra a identidade cultural" e "violência contra a pulsão criadora”. A primeira ocorre à medida que se produz padronização e homogeneização de temas e conteúdos do novo currículo, desconsiderando os conhecimentos, a experiência e os desejos prévios dos sujeitos e suas comunidades. A segunda manifesta-se quando existe a imposição de "habilidades e competências" a serem trabalhadas nos currículos, e também de itinerários com matrizes e conteúdos padronizados - no caso da escola pública, retirando dos professores e das professoras a "pulsão criadora", elemento fundamental para o exercício da docência na perspectiva da emancipação humana. 
A violência contra a autonomia também ocorre em relação aos recursos materiais nesta fase da implementação do Novo Ensino Médio nas escolas-piloto.

[...] inclusive veio isso, de que a gente ia ter autonomia para modificar a escola, para criar a sala temática. Então, assim, nós pensamos na escola dos sonhos! Eu Sonhei muito com essa escola maravilhosa, eu pensei na minha sala, né? "Na minha sala" é totalmente possessivo, mas eu pensei na sala das linguagens, com muito Drummond, com muito Mario Quintana, exposto para a gente poder trocar, tocar, poder mexer. E ai fogem essas coisas no momento em que [respondem]: "não, o dinheiro tu não podes usar com isso". Dai foi eu que fiz toda parte do recurso financeiro... vocês não têm ideia, eu não podia, "tudo não podia", foi muito complicado (SALGUEIRO, 2020).

Então não mudou em nada e aí vem todo um outro ponto a se pensar porque não é apenas a questão física, ali tem mais outro lado: e a merenda desse aluno que fica no contraturno e que vai almoçar na escola? E ai tem que oferecer lanche, a merenda e mais o almoço. Então, assim, vai muita coisa, muito dinheiro, né? Vai bastante recurso, nossa escola demanda de bastante recurso, bem complicado (SALGUEIRO, 2020).

Assim, as narrativas sobre o tema dos recursos comunicam a presença da "Violência Curricular no nível da factibilidade ética" que, conforme Giovedi (2016), se trata da violência que impede ou atrapalha a eficácia da instituição escolar no sentido de realizar os objetivos a que se propõe. Geralmente, como esclareceu o autor, essa violência se manifesta no e através do currículo quando não há as condições de funcionamento ou quando elas são insuficientes para a escola, tendo como vítimas não apenas os professores, mas os alunos também. Nesse sentido, uma mesma forma de manifestação de Violência Curricular pode representar uma outra, como ocorre neste caso, em que a falta de recursos financeiros pode ser lida como "violência contra as condições de funcionamento" e, ao mesmo tempo, como sendo uma "violência contra a vida em comunidade" (GIOVEDI, 2016).

É importante destacar que essas violências curriculares promovidas pelo NEM ocorrem devido à maior capilaridade e avanço do neoliberalismo escolar (LAVAL, 2019) e de práticas gerencialistas de regulação nas redes de ensino, que afetam o sentido e as possibilidades do exercício crítico da docência - entendendo essas práticas como "o sistema de descrição, explicação e interpretação do mundo a partir das categorias da gestão privada" (SACRAMENTO; PINHO, 2018, p. 338) ${ }^{5}$.

Como descreveu Laval, "a escola neoliberal é a designação de certo modelo escolar que considera a educação um bem essencialmente privado, cujo valor é acima de tudo

\footnotetext{
${ }^{5}$ Vale destacar, conforme observaram Lima e Gandin (2017, p. 731), que "o gerencialismo é uma concepção que busca uma transformação cultural e que, quando vivenciada no Estado, busca libertá-lo de suas amarras burocráticas, apontadas como parte de sua ineficiência, e criar a liberdade para que seus agentes gerenciem".
} 
econômico" (2019, p. 17). Um modelo que visa, nas palavras de Laval, "o enfraquecimento de tudo que serve de contrapeso ao poder do capital e tudo que, institucionalmente, juridicamente e culturalmente limita sua expansão social” (2019, p. 39). Diferentemente desse autor, que inferiu que "a escola neoliberal seria apenas uma tendência e não uma realidade consumada" (LAVAL, 2019, p. 20), acreditamos que o neoliberalismo escolar já é real e manifesto em políticas como a do Novo Ensino Médio.

Referente ao Ensino Médio, os estudos de Krawczyk (2014a; 2014b) e Silva (2008; 2018) têm demonstrado que essa etapa passou a ser um nicho importante para o mercado, tornando-se alvo de reformas e políticas curriculares baseadas em uma perspectiva economicista que produz uma formação administrada, baseada em competências, competição e competitividade, e também em uma perspectiva neotecnicista, mecanicista e utilitária do "saber fazer".

Como destacou Hipólyto (2010, p. 1346) ao analisar algumas formas de regulação da educação do estado do Rio Grande do Sul na primeira década do século XXI, "as práticas reguladoras neoliberais [...] têm levado a cabo uma série de programas estruturantes para reorganizar a gestão pública, a partir de uma abordagem gerencialista", onde propostas de reformulação curricular ganham importância estratégica. Nesse sentido, “a autonomia tem se tornado uma [...] autonomia imaginada, despersonalizada, uma docência de resultados que se confunde com profissionalismo.” Assim, o que mais interessa no exercício da docência do Novo Ensino Médio é que o professor e a professora se tornem colaboradores "para a efetiva realização dos padrões estandardizados de um currículo necessário para a reestruturação econômica do capitalismo, no atual contexto de globalização” (2010, p. 1346).

\section{O Novo Ensino Médio como violência contra o direito ao conhecimento e ao trabalho docente}

As escolas-piloto também já estão sentindo o peso da violência do novo currículo nas dimensões do trabalho docente e do direito dos alunos ao conhecimento historicamente acumulado nas áreas e componentes curriculares do Ensino Médio. A obrigatoriedade de 40\% da matriz curricular ser composta por itinerários formativos esvaziou a formação básica geral, vinculada à $\mathrm{BNCC}$, de conteúdos e tempos relativos aos conhecimentos de campos disciplinares clássicos, cujo acesso deveria ser considerado um direito das juventudes. Em todas as matrizes curriculares da rede estadual de ensino houve um acréscimo de, aproximadamente, 12 novos componentes curriculares nos percursos formativos que 
compõem a parte diversificada e uma diminuição considerável da carga horária dos componentes curriculares correspondentes à formação comum. Literatura e Arte, por exemplo, ficaram reduzidas a um único período/hora semanal de aula, apenas no $1^{\circ}$ ano do Ensino Médio; Física, Biologia, Educação Física, Sociologia e Química foram reduzidas a um período/hora semanal de aula, apenas no $1^{\circ}$ e no $2^{\circ}$ ano.

Eu sou professora de Lingua Portuguesa e Literatura Brasileira, e ai pessoal, pasmem! Eu só tenho um período de Literatura no primeiro ano, não tem Literatura no segundo e nem no terceiro. Meu aluno não precisa ler? Aí alguém vai me dizer: sim, mas ele lê em Português! Beleza, tudo bem! Ele vai aprender tudo em um ano só, no primeiro ano, no segundo e no terceiro ele não precisa? Os alunos já têm "pouca dificuldade de fazer leitura", então se tu não passar atividade diferente para eles lerem, é muito complicado. Onde é que vai parar meu "café literário" que eu faço com os meus alunos? Onde é que vai parar todas as coisas que eu faço para que eu consiga que eles leiam uma poesia? Para que eu consiga um que eles leiam alguma coisa dos contos se não vai ter essa interação com professor?" (SALGUEIRO, 2020).

Vale lembrar que a justificativa que acompanhou a reforma atual do Ensino Médio dizia que ele não mais correspondia aos anseios das juventudes em relação à inserção no mercado de trabalho, e que não contribuía para o desenvolvimento econômico do país (SILVA; SCHEIBE, 2017). Tais argumentos somaram-se a um discurso de que o Ensino Médio estava ultrapassado, com excessos de conteúdos e disciplinas obrigatórias. De certa forma, as matrizes curriculares das escolas-piloto demonstram que o novo currículo conseguiu atingir a meta gerencial e economicista da reforma, pois conteúdos e disciplinas obrigatórias foram retirados em detrimento de um aumento considerável de novos componentes através dos itinerários formativos.

Quanto ao impacto na carga horária da docência, Caroline foi enfática: "Há dois anos tínhamos 50 professores em nossa escola, agora temos 35!". Perguntada se os professores da rede pública estadual poderiam compensar essas perdas, referentes ao conhecimento comum, através dos percursos formativos, a professora respondeu que não e comentou:

Porque dai a gente vai lá na grade do percurso: onde é que estão contemplados esses conteúdos na grade do percurso? Não estão, e nem pode, porque o percurso é para ser diferente, é para ser lúdico, é para ser dinâmico, é para ser uma outra circunstância. Como é que a gente vai fazer? Então, esses detalhes são os impasses na verdade que eu observo, para mim em sala de aula, que são muito maiores porque professor é assim: a gente tem a dificuldade, sim, do novo quando chega para se adaptar, mas depois a gente se adapta, a gente vai, a gente tenta fazer o melhor (pelo menos quem é comprometido com vai fazer). No início estranhamento, mas 
depois a gente vai dar conta. Mas vocês não pensem que não passa isso na cabeça de muitos: o que que nós estamos fazendo com os nossos alunos? Porque pensamos (SALGUEIRO, 2020).

O professor da rede privada também expressou preocupação com a redução de sua carga horária. "A redução da carga horária é drástica, e isso vai impactar no fazer pedagógico sim”, diz Leandro, ponderando, entretanto, que na rede privada isso não ocorreria com tanta profundidade como na pública: "nas [escolas] particulares eu não acredito que fariam algo nesse sentido, mas eu também estou bem convicto de que os três períodos [de História] eu não vou ter mais, isso é certo" (LEANDRO, 2020). Para Leandro, uma alternativa que se apresenta em sua rede privada é "ofertar cursos formativos dentro da história", uma possibilidade de os alunos realizarem os itinerários por dentro das respectivas áreas do conhecimento. Sobre esse aspecto, destacou: "Esses dias até tinha perguntado, então a gente vai ter que elaborar cursos para a gente conseguir ter emprego? Perguntei dessa forma direta e foi dito: sim! Isso gera uma apreensão porque a tua formação não foi dessa forma" (LEANDRO, 2020).

Diferentemente do que vive Leandro em sua escola privada, onde os percursos/itinerários podem ocorrer por dentro da mesma área do conhecimento e de cursos oferecidos através dos componentes curriculares, de forma isolada ou interdisciplinar, na rede pública estadual de ensino cada percurso mescla duas áreas, com vários componentes novos que são fixos nas matrizes curriculares, com conteúdos e habilidades também preestabelecidos.

Alessandro, professor de outra escola-piloto da rede pública estadual do RS, disse que diminuiu muito sua carga horária como professor de história e que a saída foi assumir disciplinas novas vinculadas aos percursos formativos, o "que tem gerado muito trabalho extra", comentou. Além disso, segundo ele, passou a fazer parte do cotidiano do professor da escola-piloto uma dinâmica de planejamento e preenchimento de planos e documentos que exigem do docente o uso de "novas nomenclaturas":

Dentro desse Novo Ensino Médio a gente tem em mente sempre aquele
currículo de conteúdos antigos, agora não se fala mais assim... objeto do
conhecimento é como se refere aos conteúdos e componente curricular seria
história. [...] Não se usa mais objetivos, é habilidades. Não se pode mais
usar objetivos, inclusive no plano de aula seria apenas as habilidades e
transversalidades (ALESSANDRO, 2020).

Essas novas nomenclaturas operam no campo da prática, a fim de imprimir sobre a ação dos sujeitos o sentido de modernização e inovação curricular. Elas também representam 
a presença de "ideologias instrumentais", de uma "racionalidade" tecnocrática e instrumental que desenvolve papel fundamental no controle do trabalho docente, reduzindo a docência à execução de procedimentos técnicos e de conteúdos ligados ao que Giroux (1997) nomeou de "pedagogias do gerenciamento".

Nessa perspectiva, o currículo do Novo Ensino Médio é violento à medida que favorece a precarização e a descaracterização do trabalho docente, e nega às juventudes da rede pública estadual de ensino o acesso a determinados conhecimentos, reforçando a dualidade estrutural que acompanha o Ensino Médio em sua historicidade.

Nós não temos essa leitura do que nós estamos fazendo com este aluno aqui, e essa leitura, é claro que nós precisamos ter. Mas nem todo aluno quer ir para o Enem, nem todo aluno quer ir para faculdade, e tudo bem. Ele precisa ter o que? O conhecimento. Se ele não quiser usá-lo é um direito dele, mas ele o tem, e de qualidade. Eu, pelo menos, enquanto professora, me coloco nessa situação quando eu venho e faço meu trabalho - eu vou te ensinar para "isso" e quero que tu aprendas por "este motivo". Se tu não quiseres usar: ok, mas eu sei que a hora que tu quiseres fazer mão dele, ele vai estar lá. Eu acho que isso seria importante! Então ao invés de ficar inventando nomes, percursos e coisas assim, vamos oferecer o básico, mas bem oferecido, com qualidade. Isso é o que meu aluno quer. Então, não adianta eu ficar inventando muitas coisas, não adianta eu querer dizer para o meu aluno lá, por exemplo, como a gente está fazendo nosso percurso de expressão cultural, mas ele nunca teve a oportunidade de ir ao teatro? Ai eu vou dizer para ele que ele tem que cuidar da entonação, que o diafragma que vai fazer falar mais alto... como? Como é que ele vai apreciar? Então são algumas coisas que são falhas, porque daí nem o aluno acredita naquilo que a gente está falando. Como é que ele vai acreditar nisso? (SALGUEIRO, 2020).

Assim, o currículo do Novo Ensino Médio também é violento, pois através da flexibilização ocorre a negação do direito de formação comum (SILVA; SCHEIBE, 2017), privando os alunos das escolas públicas de conhecimentos que foram produzidos e acumulados pela sociedade ao longo da história e que constituem, portanto, seus patrimônios culturais (SILVEIRA; MORETTI, 2017), “enfraquecendo o sentido do ensino médio como “educação básica"” (SILVA, 2018, p. 4).

Krawczyk e Ferretti (2017, p. 36) asseveraram que a flexibilização é "a palavra de ordem" do Novo Ensino Médio. Segundos os autores, o termo vem sendo utilizado nas últimas décadas "para se opor a uma estrutura estatal de proteção do trabalho e de proteção social". E destacaram que o uso do termo flexibilização tem sido estrategicamente tentador,

[...] porque remete, na fantasia das pessoas, à autonomia, livre escolha, espaço de criatividade e inovação. Mas flexibilização pode ser também desregulamentação, precarização, instabilidade da proteção contra a 
concentração da riqueza material e de conhecimento, permitindo a exacerbação dos processos de exclusão e desigualdade social (KRAWCZYK; FERRETTI, 2017, p. 36).

Dessa forma, concluem que “a Lei 13415/2017 'flexibiliza' o tempo escolar, a organização e conteúdo curricular, o oferecimento do serviço educativo (parcerias), a profissão docente e a responsabilidade da União e dos Estados" (KRAWCZYK; FERRETTI, 2017, p. 37).

No ano de 2019, quando iniciamos a pesquisa, houve uma audiência pública do Conselho Estadual de Educação do estado do Rio Grande do Sul sobre o Novo Ensino Médio, na cidade-sede da área de abrangência de nossa investigação. O momento foi gravado com autorização da presidente do CEED-RS, que compunha a mesa e, posteriormente, foi transcrito o discurso da conselheira que apresentou o Novo Ensino Médio às escolas. Alguns excertos da transcrição do discurso que compôs aquele momento já eram sintomáticos em relação ao que Krawczyk e Ferretti (2017) anunciavam sobre a ampliação das parcerias público-privadas no Novo Ensino Médio:

Precisa se estar atento às reais necessidades dos desejos e sonhos da juventude, das possibilidades que a escola tem para oferecer [os itinerários], isso é muito importante, não dá também para sonhar lá na escola e fazer ofertas do que não há infraestrutura [...] Mas teremos os parceiros! Os parceiros irão nos ajudar a enriquecer o currículo da escola". [...] E os locais? O local natural de preferência é a escola, no entanto, podemos nos valer de inúmeras instituições credenciadas e, também, um outro local que nós conhecemos muito e que agora a lei contempla: o Ead: $20 \%$ do diurno e $30 \%$ do noturno, especialmente na educação profissional. [...] O Currículo deve ser lugar de experimentos [...] e "ser protagonista de sua vida significa olhar-se e olhar para frente" (ESTADO DO RIO GRANDE DO SUL, 2019, s/p, grifos nossos).

Sobre esse tema, o professor Leandro, da escola particular, expressou os seguintes questionamentos, que exemplificam essa dimensão da flexibilização curricular:

Porque uma das questões [...] que vai ter aquela parte flexível, que o estudante poderá escolher onde ele vai estudar. Ele pode manter a carga horária fixa [BNCC], por exemplo, no nosso colégio, mas a flexível ele pode querer fazer numa escola pública que está ofertando o itinerário formativo que ele quer para a vida dele? Isso é permitido? Essa foi uma das dúvidas que os professores levantaram. Então, qual é o vínculo que o estudante vai ter com a escola, do início ao fim do processo?" [...] "Pode ser que certas famílias optem por ter uma parte da formação mais rígida, em que vai se manter os componentes curriculares, que ele pode pegar [ou pagar] aquela parte fixa dos componentes curriculares [...] em uma [escola] particular, por exemplo, e o itinerário formativo ele pode querer fazer ou numa outra particular ou numa pública, isso é permitido? [...] $O$ que as escolas particulares ofertarão? E querendo ou não, elas estão preocupadas com a 
questão de ofertar um serviço que atraia os estudantes, porque é um comércio. É diferente das públicas, a preocupação deles é outra, e isso ficou bem presente nas falas que nós tivemos nas nossas formações" (LEANDRO, 2020).

As narrativas dos sujeitos permitem compreender que a processualidade do NEM tem se ancorado na naturalização dos problemas estruturais das escolas ("não dá também para sonhar lá na escola e fazer ofertas do que não há infraestrutura...”, como disse a conselheira), ao mesmo tempo em que amplia a porosidade para a influência do Terceiro Setor na escola pública ("Mas teremos os parceiros! Os parceiros irão nos ajudar a enriquecer o currículo da escola", como ela também declarou). Esse tema também poderia ser analisado em relação ao aquecimento do mercado editorial dos livros didáticos para o Novo Ensino Médio, onde já estão sendo distribuídas diferentes coleções que passaram a desempenhar um importante papel na implementação da Lei 13.415/2017 (BRASIL, 2017).

De forma geral, a recente reforma do Ensino Médio ocorre em um momento de intensificação de "uma minimização do papel do Estado para com as políticas sociais e um longo processo de privatização e mercantilização do público" (PERONI, 2012, p. 39). É um contexto que também favorece a proliferação desses "parceiros", pois se trata de um "gradativo aumento do número de instituições não estatais que se fazem presentes na relação entre Estado e Educação", como concluíram Lima e Gandin (2017, p. 744) ao analisarem a dispersão do poder do Estado na intensificação do gerencialismo nas políticas educacionais. Neste cenário, aprofunda-se a mudança de finalidade da docência e da formação como um todo. Desse modo, a escola abandona uma lógica de conhecimentos em prol de uma lógica de competências, dando mais prioridade às qualidades diretamente úteis de uma personalidade supostamente empregável e, ao mesmo tempo, aumentando efeitos como a desintelectualização, a desespecialização e a desformalização do processo de aprendizagem (LAVAL, 2019).

Cada vez mais, as qualidades mais importantes exigidas no mundo do trabalho e aquelas que as empresas querem encorajar as escolas a ensinar, são de ordem mais geral. A adaptabilidade, a faculdade da comunicação, a de trabalhar em equipe, de mostrar iniciativa empreendedora - essas qualidades e outras competências "genéricas" - são, agora, essenciais para assegurar a competitividade das empresas (LAVAL, 2004, p. 59). Assim, "competências", "habilidades socioemocionais", "educação financeira", "itinerários formativos", “flexibilização", são palavras que compõem o glossário do Novo Ensino Médio e que, como comentou Silva (2021, s/p), "são palavras que fazem parte de um léxico e de uma racionalidade que as enclausuram nas lógicas que as produziram. Assim, não é possível 
ressignificar a palavra competência de forma que ela tenha um sentido emancipatório". Como também observou essa pesquisadora, "falar de educação financeira para pobre é de um cinismo sem tamanho - é dizer para os filhos da pobreza que o problema deles e o que falta na escola é educação financeira, que ele precisa aprender a economizar o que já não tem" (SILVA, 2021, s/p).

As narrativas dos sujeitos entrevistados, como vimos, representam formas de violência curricular à medida que lesam o direito ao conhecimento e ao trabalho com dignidade e em comunidade. Nesta seção, essas formas de violência também integram modos específicos de manifestação da Violência Curricular identificados por Giovedi (2016), entre os quais: a "violência contra as condições de funcionamento" da escola, "violência contra a pulsão de autoconservação", "contra a integridade moral e psíquica" e "contra o desenvolvimento da potencialidade intelectual" - sendo esta última mais presente em relação aos docentes à medida que os procedimentos citados nas entrevistas referem-se indiretamente à negação do papel dos professores enquanto intelectuais transformadores (GIROUX, 1997). Nesse sentido, o exercício da docência se vê confrontado com dilemas éticos e políticos, pois, afinal de contas, como questionou a supervisora Caroline, "talvez essa seja uma das maiores perguntas: ‘para quê é o Novo Ensino Médio?"’ (SALGUEIRO, 2020).

\section{Considerações finais}

Neste artigo, compreendemos o que comunicam as narrativas de professores(as) de escolas-piloto a respeito da docência e do currículo do chamado Novo Ensino Médio no campo da prática, identificando as violências que se manifestam nesse novo currículo para o exercício da docência na perspectiva da emancipação humana. Argumentamos que o currículo proposto pela reforma tem produzido diferentes formas e manifestações de Violência Curricular e, por esse motivo, impõe obstáculos ao exercício da docência e à formação em perspectiva crítica.

O exercício da docência, nesta perspectiva, implicaria possibilidades concretas de participar da emancipação das pessoas, tornando-as mais livres e não reduzindo sua formação às lógicas de uma racionalidade instrumental e economicista. No entanto, o projeto formativo em ação no Novo Ensino Médio indica diferentes formas de violência curricular nas escolaspiloto que, na prática, configuram-se como obstáculos ao sentido emancipatório da docência no currículo escolar. A docência neste projeto fica reduzida à execução de procedimentos técnicos e de conteúdos ligados às competências padronizadas e alinhadas com as 
necessidades econômicas atuais, e com uma concepção de formação para adaptação, para a flexibilização e para a competitividade.

Conforme categorizado por Giovedi, podemos identificar que as narrativas dos entrevistados comunicam diferentes formas de manifestação dessa violência, pois esse novo currículo nega aos sujeitos do Ensino Médio o direito à autonomia, ao conhecimento e ao trabalho de maneira digna, humana e em comunidade, abrindo brechas para que o Ensino Médio público seja enfraquecido enquanto etapa final da educação básica e enquanto direito para as juventudes e trabalhadores(as) da educação.

AGRADECIMENTOS: aos sujeitos entrevistados e aos bolsistas de iniciação científica que participam desta etapa da pesquisa; ao apoio recebido pelo Conselho Nacional de Desenvolvimento Científico e Tecnológico (CNPq - Brasil).

\section{REFERÊNCIAS}

ADORNO, T. W. Educação e emancipação. Trad. Wolfgang Leo Maar. Rio de Janeiro, RJ: Paz e Terra, 1995.

ALESSANDRO, Professor. Narrativas de professores(as) de História sobre o Novo Ensino Médio. [Entrevista concedida a] Leonardo Müller Frantz e Grupo de Pesquisa Currículo, Memórias e Narrativas em Educação. 116min. Grav. via google meet, 2020. Acervo do Grupo de Pesquisa Currículo, Memórias e Narrativas em Educação-CNPq. Santa Cruz do Sul, RS, 19 ago. 2020.

APPLE, M. W. A política do conhecimento oficial: faz sentido a ideia de um currículo nacional? In: MOREIRA, A. F.; TADEU, T. Currículo, cultura e sociedade. São Paulo, SP: Cortez, 2011. p. 71-106.

APPLE, M. W. Ideologia e currículo. Porto Alegre, RS: Artmed, 2006.

APPLE, M. W.; AU, W.; GANDIN, A. L. O mapeamento da educação crítica. In: APPLE, M. W.; AU, W.; GANDIN, A. L. (Org.). Educação crítica. Porto Alegre, RS: Artmed, 2011. p. 14-32.

ARROYO, M. G. Currículo, território em disputas. Petrópolis, RJ: Vozes, 2013.

BARDIN, L. Análise de conteúdo. São Paulo, SP: Almedina, 2011.

BRASIL. Lei n. 9.394, de 20 de dezembro de 1996. Estabelece as diretrizes e bases da educação nacional. Brasília, DF, 23 dez. 1996. Disponível em:

http://www.planalto.gov.br/ccivil_03/LEIS/L9394.htm. Acesso em: 10 mar. 2021. 
BRASIL. Lei n. 13.415, de 16 de fevereiro de 2017. Altera as Leis ${ }^{\circ}{ }^{9} 9.394$, de 20 de dezembro de 1996, que estabelece as diretrizes e bases da educação nacional, e 11.494, de 20 de junho 2007, que regulamenta o Fundo de Manutenção e Desenvolvimento da Educação Básica e de Valorização dos Profissionais da Educação, a Consolidação das Leis do Trabalho - CLT, aprovada pelo Decreto-Lei $n^{0} 5.452$, de $1^{\circ}$ de maio de 1943, e o Decreto-Lei $\mathrm{n}^{\circ} 236$, de 28 de fevereiro de 1967; revoga a Lei $\mathrm{n}^{\circ}$ 11.161, de 5 de agosto de 2005; e institui a Política de Fomento à Implementação de Escolas de Ensino Médio em Tempo Integral. Brasília, DF, 17 fev. 2017. Disponível em: http://www.planalto.gov.br/ccivil_03/_ato2015-2018/2017/lei/113415.htm. Acesso em: 24 mar. 2021.

BRASIL. Ministério da Educação. Portaria n. 649, de 10 de julho de 2018. Estabelece o Programa de Apoio ao Novo Ensino Médio. Brasília, DF: MEC, 11 jul. 2018a.Disponível em: https://www.in.gov.br/materia/-/asset_publisher/Kujrw0TZC2Mb/content/id/29495231/do12018-07-11-portaria-n-649-de-10-de-julho-de-2018-29495216. Acesso em: 24 mar. 2021.

BRASIL. Conselho Nacional de Educação; Câmara de Educação Básica. Resolução n 3, de 21 de novembro de 2018. Atualiza as Diretrizes Curriculares Nacionais para o Ensino Médio. Brasília, DF: CNE, CEB, 22 nov. 2018b. Disponível em:

http://www.planalto.gov.br/ccivil_03/_Ato2015-2018/2017/Lei/L13415.htm. Acesso em: 20 fev. 2021.

BRASIL. Ministério da Educação. Portaria n. 1.432, de 28 de dezembro de 2018.

Estabelece os referenciais para elaboração dos itinerários formativos conforme preveem as Diretrizes Nacionais do Ensino Médio. Brasília, DF: MEC, 31 dez. 2018c. Disponível em: https://www.in.gov.br/materia/-/asset_publisher/Kujrw0TZC2Mb/content/id/57496579/do12018-12-31-portaria-n-1-432-de-28-de-dezembro-de-2018-57496288. Acesso em: 11 mar. 2021.

BRASIL. Ministério da Educação. Base Nacional Comum Curricular. Brasília, DF: MEC, 2018d. Disponível em:

http://basenacionalcomum.mec.gov.br/images/BNCC_EI_EF_110518_versaofinal_site.pdf. Acesso em 09 mar. 2021.

CANDAU, V. M. Diretos humanos, violência e cotidiano escolar. In: CANDAU, V.M.

Reinventar a escola. Petrópolis, RJ: Vozes, 2000. p. 137-166.

DUSSEL, H. 1492, o encobrimento do outro: a origem do mito da modernidade. Rio de janeiro, RJ: Vozes, 1993.

ESTADO DO RIO GRANDE DO SUL. CONSELHO ESTADUAL DE EDUCAÇÃO. Audiência Pública do Conselho Estadual de Educação: RS sobre o Novo Ensino Médio. $18^{\text {a }}$ Sessão Plenária fora da sede. Santa Cruz do Sul, RS, 28 ago. 2019.

FREIRE, P. Pedagogia do oprimido. São Paulo, SP: Paz e Terra, 2005.

GIOVEDI, V. M. Violência curricular e a práxis libertadora na escola pública. Curitiba, PR: Appris, 2016. 
GIROUX, H. Teoria crítica e resistência em educação: para além das teorias de reprodução. Petrópolis, RJ: Vozes, 1986.

GIROUX, H. "Professores como intelectuais transformadores". In: GIROUX, H. Os

professores como intelectuais: rumo a uma pedagogia crítica da educação. Porto Alegre, RS: Artes Médicas, 1997. p. 157-164.

HYPOLITO, Á. M. Políticas Curriculares, Estado e Regulação. Educ. Soc., Campinas (SP), v. 31, n. 113, p. 1337-1354, out./dez. 2010.

IMBERNÓM, F. Formação docente e profissional: formar-se para a mudança e a incerteza. São Paulo, SP: Cortez, 2001.

KRAWCZYK, N. Ensino médio: empresários dão as cartas na escola pública. Educ. Soc., Campinas (SP). v. 35, n. 126, p. 21-41, 2014a. DOI: doi.org/10.1590/S010173302014000100002

KRAWCZYK, N. Sociologia do ensino médio: crítica ao economicismo na política educacional. São Paulo, SP: Cortez, 2014b.

KRAWCZYK, N; FERRETTI, C. J. Flexibilizar para quê? Meias verdades da "reforma". Revista Retratos da Escola, Brasília (DF), v. 11, n. 20, p. 33-44, jan./jun. 2017.

LAVAL, C. A escola não é uma empresa: o neoliberalismo em ataque ao ensino público. São Paulo, SP: Boitempo, 2019.

LEANDRO, Professor. Narrativas de professores(as) de História sobre o Novo Ensino Médio. [Entrevista concedida a] Leonardo Müller Frantz e Grupo de Pesquisa Currículo, Memórias e Narrativas em Educação. 100min. Grav. via google meet, 2020. Acervo do Grupo de Pesquisa Currículo, Memórias e Narrativas em Educação-CNPq. Santa Cruz do Sul, RS, 12 ago. 2020.

LIMA, I. G.; GANDIN, L. A. Gerencialismo e dispersão de poder na relação Estadoeducação: as traduções e os hibridismos do caso brasileiro. RBPAE - Revista Brasileira de Política e Administração da Educação, Brasília, DF, v. 33, n. 3, p. 729-749, set./dez. 2017. DOI: doi.org/10.21573/vol33n32017.79305

LIMA, J. G. S. A.; PERNAMBUCO, M. M. C. Horizontes pós-coloniais da Pedagogia do Oprimido e suas contribuições para os estudos curriculares. Revista Brasileira de Educação, v. 23, e230063, 2018. DOI: doi.org/10.1590/S1413-24782018230063

NOBRE, M. A Teoria Crítica. Rio de Janeiro: Zahar, 2004.

PERONI, V. M. V. Reforma do Estado e políticas públicas educacionais no Brasil. Revista Educação e Políticas em Debate, Uberlândia (MG), v. 1, n. 1, jan./jul. 2012. Disponível em: http://www.seer.ufu.br/index.php/revistaeducaopoliticas/article/view/17362. Acesso em: 24 mar. 2021.

PORTELli, A. O que faz a história oral diferente. Projeto História, São Paulo, n. 14, p.2539, fev. 1997. 
PORTELLI, A. História oral como gênero. Projeto História, São Paulo (SP), n. 22, p. 9-36, jun. 2001. Disponível em: https://revistas.pucsp.br/index.php/revph/article/view/10728. Acesso em: 21 mar. 2021.

PUCCI, B. Teoria crítica e educação. In: PUCCI, B (Org.) Teoria crítica e educação: a questão da formação cultural na Escola de Frankfurt. Rio de Janeiro, RJ: Vozes, 1995. p. 4659.

SACRAMENTO, A. R. S.; PINHO, J. A. G.; Gerencialismo. In: GIOVANNI, G. D.; NOGUEIRA, M. A. Dicionário de políticas públicas. 3. ed. São Paulo, SP: Editora UNESP, 2018. p. 388-392.

SALGUEIRO, C. Experiências e desafios da escola-piloto do Novo Ensino Médio. [Entrevista concedida a] Éder da Silva Silveira e Grupo de Pesquisa Currículo, Memórias e Narrativas em Educação - CNPq. 84min. Grav. via google meet, 2020. Santa Cruz do Sul, RS, 8 out. 2020.

SAUL, A. M. Currículo. In: STRECK, D. R.; REDIN, E.; ZITKOSKI, J. J. Dicionário Paulo Freire. Belo Horizonte, MG: Autêntica Editora, 2015. p. 222.

SILVA, M. R. Currículo e Competências: a formação administrada. São Paulo, SP: Cortez, 2008 .

SILVA, M. R. A BNCC da reforma do ensino médio: o resgate de um empoeirado discurso. Educ. rev., Belo Horizonte (MG), v. 34, e214130, 2018. DOI: doi.org/10.1590/01024698214130

SILVA, M. R. Comentários sobre o conceito de competência. Registro de fala da pesquisadora proferida em reunião do Observatório do Ensino Médio. Curitiba, PR: Universidade Federal do Paraná, 22 fev. 2021.

SILVA, M. R. Comentários sobre o currículo do Novo Ensino Médio. Registro de fala da pesquisadora durante bancas públicas virtuais de trabalho de conclusão de curso. Curitiba, PR: Universidade Federal do Paraná, 11 fev. 2021.

SILVA, M. R; SCHEIBE, L. Reforma do ensino médio. Pragmatismo e lógica mercantil. Revista Retratos da Escola, Brasília (DF), v. 11, n. 20, p. 19-31, jan./jun. 2017. DOI: doi.org/10.22420/rde.v11i20.769

SILVEIRA, É. S.; MORETTI, C. Z. Ensino médio para quem? A falácia do discurso da escolha e o reforço da dualidade estrutural. Revista Textual, Porto Alegre (RS), v. 25, p. 3035, maio 2017.

SILVEIRA, É. S.; RAMOS, N. V.; VIANNA, R. B. O “novo” ensino médio: apontamentos sobre a retórica da reforma, juventudes e o reforço da dualidade estrutural. Revista Pedagógica, Chapecó (SC), v. 20, n. 43, p. 101-118, jan./abr. 2018.

VEIGA, I. P. A. Docência: uma construção ético-profissional. Campinas, SP: Papirus, 2005. 


\section{Como referenciar este artigo}

SILVEIRA, É. S.; SILVA, M. R.; OLIVEIRA, F. L. B. Reformas, docência e violência curricular: uma análise a partir do "Novo Ensino Médio". Revista Ibero-Americana de Estudos em Educação, Araraquara, v. 16, n. esp. 3, p. 1562-1585, jun. 2021. e-ISSN: 19825587. DOI: https://doi.org/10.21723/riaee.v16iesp.3.15298

Submissão em: 05/02/2021

Revisões requeridas em: 30/03/2021

Aprovado em: 12/05/2021

Publicado em: 01/06/2021 